\title{
Cytotoxicity and ROS production of novel Pt(IV) oxaliplatin derivatives with indole propionic acid
}

\author{
Dina Tolan ${ }^{\mathrm{a}, 1,2}$, Awatif Rashed Z. Almotairy ${ }^{\mathrm{a}, \mathrm{b}, 1}$, Orla Howe ${ }^{\mathrm{b}}$, Michael Devereux ${ }^{\mathrm{b}}$, \\ Diego Montagner ${ }^{\mathrm{c}, *}$, Andrea Erxleben ${ }^{\mathrm{a}, *}$

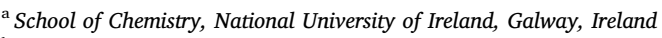 \\ ${ }^{\mathrm{b}}$ School of Biological \& Health Sciences, Technological University Dublin, City Campus, Dublin, Ireland \\ ${ }^{\mathrm{c}}$ Department of Chemistry, Maynooth University, Maynooth, Ireland
}

\section{A R T I C L E IN F O}

\section{Keywords:}

Oxaliplatin

$\mathrm{Pt}(\mathrm{IV})$ prodrugs

Redox stress

Indole propionic acid

Cytotoxicity

\begin{abstract}
A B S T R A C T
The coordination of biologically active moieties to the axial positions of $\mathrm{Pt}(\mathrm{IV})$ derivatives of Pt(II) anticancer drugs allows the co-delivery and simultaneous activation of two pro-drugs for combination therapy. Pt(IV) complexes with a redox modulator as an axial ligand can kill cancer cells by a mechanism combining DNA platination and generation of oxidative stress. In this study we evaluated the cytotoxicity of Pt(IV) complexes based on the oxaliplatin scaffold and the pro-oxidant indole-3-propionate in cisplatin-sensitive and cisplatinresistant ovarian cancer cells. A series of five complexes was synthesized and characterized by ${ }^{1} \mathrm{H}$ and ${ }^{195} \mathrm{Pt}$ NMR spectroscopy, IR spectroscopy, mass spectrometry and elemental analysis; trans-[Pt(DACH)(ox)(IPA)(OH)] (1), trans-[Pt(DACH)(ox)(IPA) 2$]$ (2), trans-[Pt(DACH)(ox)(IPA)(bz)] (3), trans-[Pt(DACH)(ox)(IPA)(suc)] (4), and trans-[Pt(DACH)(ox)(IPA)(ac)] (5) (DACH = 1,2-diaminocyclohexane (1R,2R)- $(-)$, ox = oxalate, IPA = indole3-propionate, $\mathrm{bz}=$ benzoate, suc $=$ succinate and ac $=$ acetate $)$. The complexes were shown to produce cellular reactive oxygen species (ROS) in a time-dependent manner. The most potent ROS producer, complex 1, also elicited the highest cytotoxicity. Complex 1 was shown to form the mono- and bis-adducts [Pt(DACH)(guanosine $(\mathrm{OH})]^{+}$and $\left[\mathrm{Pt}(\mathrm{DACH})(\text { guanosine })_{2}\right]^{2+}$ in the presence of ascorbic acid, suggesting that on activation the released oxaliplatin will interact with DNA.
\end{abstract}

\section{Introduction}

About $50 \%$ of cancer patients who undergo chemotherapy receive one of the three worldwide approved platinum(II) complexes, cisplatin, carboplatin and oxaliplatin, either alone or in combination with other anticancer drugs [1]. Co-administration of two or more chemotherapeutics with independent modes of action is widely used to reduce the risk of resistance development and to enhance the anticancer efficacy through synergistic effects [2]. However, different selectivities and pharmacokinetics of the individual drugs can pose significant challenges in the application of combination therapy regimens. Oxidation of $\mathrm{Pt}(\mathrm{II})$ to Pt(IV) allows the covalent attachment of a second biologically active entity to the axial positions of the cisplatin-, carboplatin- or oxaliplatin-scaffold [3-20]. In addition to the simultaneous delivery of the Pt drug and the co-administered drug, Pt(IV) complexes have the advantages of a higher stability, lower toxicity, reduced side effects and potential for oral administration [3,4]. Dual-action Pt(IV) compounds are pro-drugs that require activation by intracellular reducing agents to release the active Pt(II) species and the axial ligands (Chart 1) [3,21].

We have recently reported that the coordination of indole carboxylic acids to the axial positions of the Pt(IV) derivative of cisplatin leads to potent anticancer agents that overcome cisplatin resistance [22]. Indole carboxylic acids are redox modulators that can act as prooxidants [23-27]. Indole acetic acid, for example, is used in the oxidation therapy of cancer [23]. We showed that the Pt(IV) indole-3propionic acid complexes cis,cis, trans- $\left[\mathrm{Pt}\left(\mathrm{NH}_{3}\right)_{2} \mathrm{Cl}_{2}(\mathrm{IPA})(\mathrm{OH})\right]$, cis, cis,trans $-\left[\mathrm{Pt}\left(\mathrm{NH}_{3}\right)_{2} \mathrm{Cl}_{2}(\mathrm{IPA})_{2}\right], \quad$ cis, cis, trans $-\left[\mathrm{Pt}\left(\mathrm{NH}_{3}\right)_{2} \mathrm{Cl}_{2}(\mathrm{IPA})(\mathrm{Bz})\right]$ and cis, cis, trans- $\left[\mathrm{Pt}\left(\mathrm{NH}_{3}\right)_{2} \mathrm{Cl}_{2}\right.$ (IPA)(Ac)] (IPA = indole-3-propionate, $\mathrm{Bz}=$ benzoate, $\mathrm{Ac}=$ acetate) exert their cytotoxic activity by a dual-action mechanism combining DNA platination and the generation of reactive oxygen species (ROS). cis, cis, trans- $\left[\mathrm{Pt}\left(\mathrm{NH}_{3}\right)_{2} \mathrm{Cl}_{2}(\mathrm{IPA})(\mathrm{OH})\right]$ was found to be up to four times more effective than cisplatin [22].

\footnotetext{
* Corresponding authors.

E-mail addresses: diego.montagner@nuigalway.ie (D. Montagner), andrea.erxleben@nuigalway.ie (A. Erxleben).

${ }^{1}$ These authors contributed equally to this manuscript.

${ }^{2}$ Present address: Department of Chemistry, Faculty of Science, El-Menoufia University, Shebin El-Kom, Egypt.
} 
<smiles>N[PH3](N)(Cl)Cl</smiles>

cisplatin

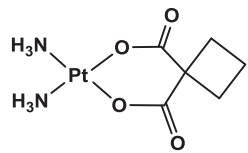

carboplatin

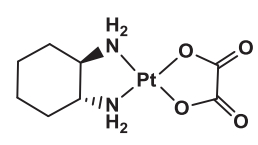

oxaliplatin<smiles></smiles>

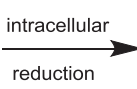<smiles>N[PH3](N)(Cl)Cl</smiles>

inactive Pt(IV) pro-drug active $\mathrm{Pt}(\mathrm{II})$ drug and active $\mathrm{L}$
Chart 1. The three FDA-approved Pt(II) anticancer drugs, general structure of Pt(IV) pro-drugs for cisplatin and pro-drug activation by reduction.

Oxaliplatin (Chart 1) is a third-generation Pt(II) drug that is approved for the treatment of metastatic colorectal cancer and is also active against lung and ovarian cancer cell lines $[28,29]$. It contains a more stable leaving group compared to cisplatin and the $R, R$-diaminocyclohexane (DACH) chelating ligand [30]. The latter leads to a spectrum of activity that is different from that of cisplatin and carboplatin. Oxaliplatin also shows a different resistance profile and is usually better tolerated than cisplatin [31,32]. In continuation of our previous work we therefore synthesized the oxaliplatin analogues of the cis,cis, trans- $\left[\mathrm{Pt}\left(\mathrm{NH}_{3}\right)_{2} \mathrm{Cl}_{2}(\mathrm{IPA}) \mathrm{Y}\right]$ complexes and investigated their cytotoxicity and ROS generating capability in cisplatin-sensitive and cisplatin-resistant ovarian cancer cells.

\section{Results and discussion}

The five complexes based on oxaliplatin (Chart 2) were synthesised as shown in Scheme 1 and in the Experimental Section in the Supporting Information. Briefly, oxaliplatin was oxidised to the corresponding di-hydroxido $\mathrm{Pt}\left(\mathrm{IV}\right.$ ) complex (A) by $\mathrm{H}_{2} \mathrm{O}_{2}$ in aqueous solution (Scheme 1). A was reacted with the activated $N$-hydroxysuccinimide (NHS) ester of indole-3-propionic acid (B) in DMSO solution to obtain complex 1. This complex was the precursor to obtain complexes 3-5 that could be isolated by precipitation with diethyl ether from a DMF solution containing 1 and the corresponding anhydride; benzoic (3), succinic (4) and acetic (5) anhydride, respectively. 2 was obtained by reaction of A with a large excess of $\mathbf{B}$ in DMSO.

The complexes were characterized by ${ }^{1} \mathrm{H}$ and ${ }^{195} \mathrm{Pt}$ NMR spectroscopy, infra-red spectroscopy, elemental analysis and mass spectrometry (Supporting Information, Figures $1 S-12 S$ ). The purity and the stability of the complexes for $36 \mathrm{~h}$ have been evaluated in HEPES buffer solution by HPLC (Fig. 13S). Elemental analyses are in good agreement with the expected values for the complexes. In the ESI-MS spectra the $[\mathrm{M}-\mathrm{H}]^{-}$or $[\mathrm{M}+\mathrm{Cl}]^{-}$parent ions of the platinum(IV) complexes were readily observed with the typical isotope pattern of Pt. The IR spectra displayed characteristic $\mathrm{C}=\mathrm{O}$ stretching vibrations around $1710 \mathrm{~cm}^{-1}$ and $1650 \mathrm{~cm}^{-1}$ for all the complexes while the symmetric and antisymmetric $\mathrm{N}-\mathrm{H}$ stretching bands of the amine ligands were found between 3325 and $3400 \mathrm{~cm}^{-1}$ and between 3150 and $3190 \mathrm{~cm}^{-1}$. The proton resonances of the coordinated amine ligands in the ${ }^{1} \mathrm{H}$ NMR spectrum of 1 appear as multiplet at $c a$. 7.08-8.52-ppm. This multiplet is broadened and downfield shifted to ca. 8.12-8.55 ppm in complexes 2-5. The chemical shift values of the amine protons are well in line with those of previously reported $\mathrm{Pt}(\mathrm{IV})$ complexes based on oxaliplatin $[33,34]$. The ${ }^{195} \mathrm{Pt}$ NMR spectrum of $\mathbf{1}$ in DMF (insert $\mathrm{D}_{2} \mathrm{O}$ ) shows a single resonance at $1389 \mathrm{ppm}$ that is shifted downfield to $c a .1590 \mathrm{ppm}$ in the di-carboxylato complexes $\mathbf{2 - 5}$. The presence of an additional electron withdrawing carboxylate ligand in 2-5 causes a de-shielding effect of about $200 \mathrm{ppm}$ on the platinum signal with respect to the mono-carboxylated complex 1.

The anticancer activities of the complexes were evaluated in two human ovarian carcinoma cells lines, cisplatin-sensitive A2780 and cisplatin-resistant A2780cis. The cytotoxicity was determined after incubation for 24 and $48 \mathrm{~h}$ using the colorimetric MTT assay and IC $_{50}$ values are reported in Table 1 . For comparison purposes, the cytotoxicities of cisplatin, oxaliplatin and of the free IPA ligand were assessed under the same experimental conditions. The complexes are less active than cisplatin, in particular in the sensitive A2780 cell line, whereas they show higher activity than the reference drug oxaliplatin. The $\mathrm{IC}_{50}$ values of 1-5 in the A2780 cells are about 3 to 6 times lower at the $48 \mathrm{~h}$ timepoint than at the $24 \mathrm{~h}$ timepoint. The decrease in the $\mathrm{IC}_{50}$ value with prolonged exposure time is less pronounced for cisplatin. That is, the oxaliplatin derivatives take longer to exert their cytotoxic effects. After $48 \mathrm{~h}$, the activity of 1 is comparable to that of cisplatin $\left(\mathrm{IC}_{50}(48 \mathrm{~h})=12.6\right.$ (1) vs. 10.5 (cisplatin)). The complexes show crossresistance with cisplatin.

In the A2780 cell line the most active complex at the $48 \mathrm{~h}$ timepoint is the mono-carboxylated complex $\mathbf{1}$ with one axial $\mathrm{OH}$ group. The bissubstituted complex 2 with two indole acids in both the axial positions<smiles>O=C1CCc2c([nH]c3ccccc23)NP(O)(O)(NC2CCCC2)OC1=O</smiles>

1

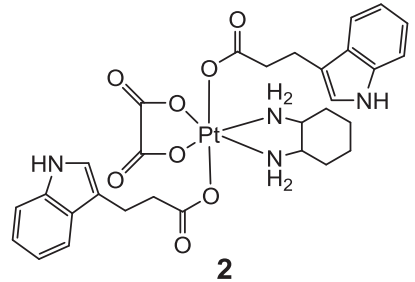

2

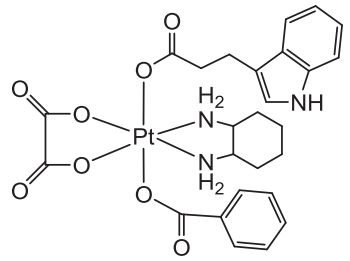

3

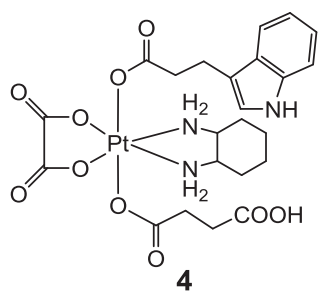<smiles>CC(=O)O[PH](NC1CCCC1)(OC(=O)CCc1c[nH]c2ccccc12)OC(=O)C(=O)O</smiles>

Chart 2. Structures of complexes 1-5. 


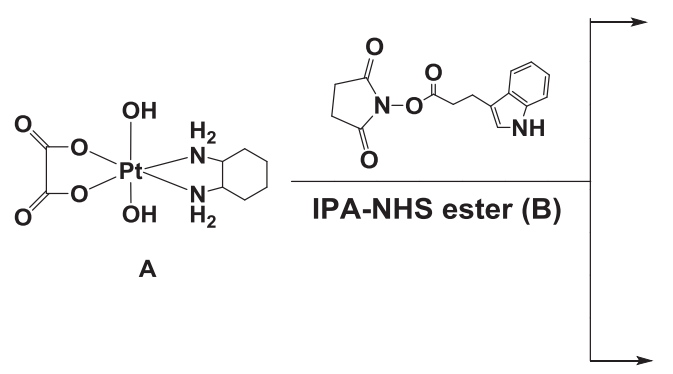

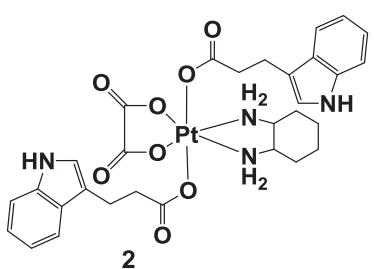

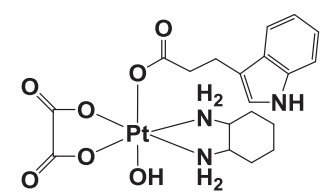

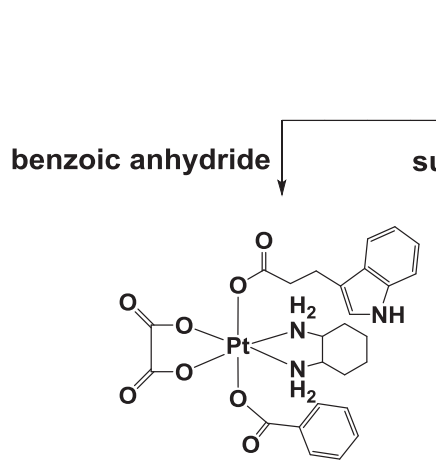

3

Scheme 1. Syntheses of complexes 1-5.

Table 1

$\mathrm{IC}_{50}$ values of the $\mathrm{Pt}(\mathrm{IV})$ complexes 1-5, cisplatin, oxaliplatin and the free ligand IPA in A2780 and A2780cis cells determined by the MTT test.

\begin{tabular}{|c|c|c|c|c|}
\hline \multirow[t]{3}{*}{ Complex } & \multicolumn{4}{|c|}{$\mathrm{IC}_{50}(\mu \mathrm{M}) \pm$ S.D. } \\
\hline & \multicolumn{2}{|l|}{ A2780 } & \multicolumn{2}{|l|}{ A2780cis } \\
\hline & $24 \mathrm{~h}$ & $48 \mathrm{~h}$ & $24 \mathrm{~h}$ & $48 \mathrm{~h}$ \\
\hline 1 & $74.40 \pm 8.1$ & $12.62 \pm 0.02$ & $66.91 \pm 1.8$ & $55.68 \pm 1.7$ \\
\hline 2 & $53.32 \pm 1.8$ & $15.47 \pm 1.72$ & $70.48 \pm 1.83$ & $46.17 \pm 1.61$ \\
\hline 3 & $54.52 \pm 1.7$ & $16.10 \pm 1.8$ & $55.26 \pm 2.30$ & $54.59 \pm 2.5$ \\
\hline 4 & $58.39 \pm 8.7$ & $16.55 \pm 8.5$ & $132.52 \pm 2.7$ & $63.69 \pm 7.4$ \\
\hline 5 & $70.10 \pm 4.65$ & $21.45 \pm 2.7$ & $103.01 \pm 6.1$ & $47.56 \pm 0.68$ \\
\hline Cisplatin & $20.10 \pm 4.65$ & $10.46 \pm 2.1$ & $60.80 \pm 8.2$ & $29.04 \pm 6.7$ \\
\hline $\begin{array}{l}\text { Oxaliplatin } \\
\text { IPA }\end{array}$ & $\begin{array}{l}83.25 \pm 5.7 \\
>200\end{array}$ & $\begin{array}{l}19.80 \pm 1.10 \\
>200\end{array}$ & $\begin{array}{l}110.68 \pm 16.8 \\
>200\end{array}$ & $\begin{array}{l}86.37 \pm 2.9 \\
>200\end{array}$ \\
\hline
\end{tabular}

is slightly more active in the resistant cells ( $48 \mathrm{~h}$ timepoint). The finding that the mono- and the bis-PBA complex exert the strongest cytotoxic activity is in line with the cytotoxicity data observed for the analogous cisplatin-based complexes [22].

The generally not exceptional activity of these complexes may be ascribed to the reduction rate of these complexes under physiological conditions. As mentioned in the introduction, Pt(IV) complexes are prodrugs and must be reduced to active Pt(II) agents. The reduction of 1 was studied via HPLC in the presence of an excess of ascorbic acid in HEPES buffer at pH 7 and $37^{\circ} \mathrm{C}$. As shown in Fig. 1, the complex releases the axial IPA ligand and is reduced to the active oxaliplatin(II) species. However, the reduction kinetics are much slower compared to the analogous Pt(IV) compound based on cisplatin [22]. After $72 \mathrm{~h}$ there is still $19 \%$ of the starting $\mathrm{Pt}(\mathrm{IV})$ complex 1 . Under the same conditions, cis,cis, trans- $\left[\mathrm{Pt}\left(\mathrm{NH}_{3}\right)_{2} \mathrm{Cl}_{2}(\mathrm{IPA})(\mathrm{OH})\right]$ was completely reduced within $24 \mathrm{~h}$ [22]. A lower reduction rate corresponds to a lower cytotoxicity because the active oxaliplatin is not completely released. In general, a low cytotoxic activity can also be due to a low lipophilicity and poor cellular uptake. However, we did not further investigate this possibility, as for the analogous cisplatin derivatives no correlation between lipophilicity, cellular uptake and $\mathrm{IC}_{50}$ value was observed. The slow pro-drug activation is consistent with the delayed cytotoxicity of $\mathbf{1}$ whose $\mathrm{IC}_{50}$ value becomes comparable to that of cisplatin at the $48 \mathrm{~h}$ timepoint.

To further confirm the activation mechanism, 1 was incubated with guanosine $(\mathrm{G})$ in the presence of sodium ascorbate to simulate the interaction of the platinum drug with the nucleobases of DNA. The mass spectrum of the reaction mixture (Fig. 2) clearly shows the presence of two peaks, corresponding to the species $\left[\mathrm{Pt}(\mathrm{DACH})(\mathrm{G})_{2}\right]^{2+}(\mathrm{m} / \mathrm{z}$ 875.25; $\left.\{\mathrm{M}-\mathrm{H}\}^{+}\right)$and $[\mathrm{Pt}(\mathrm{DACH})(\mathrm{OH})(\mathrm{G})]^{+}(m / z$ 609.16) which suggests that 1 can bind to the guanosine residues of DNA upon reduction. (Chart S1). The peak observed at $m / z=742.22$ can be assigned to $\left[\mathrm{Pt}(\mathrm{DACH})(\text { guanosine)(guanine)-H }]^{+}\right.$resulting from the loss of the sugar entity of one guanosine ligand. It is worthy of note that the incubation of 1 with guanosine without the reducing agent ascorbic acid does not give any Pt-guanosine adducts.

Indole carboxylic acids are agents that can alter and modify the cellular redox state and the cisplatin analogues of 1-5 induced a significant increase in ROS production. We speculated that the oxaliplatinbased Pt(IV) complexes with axial indole propionate ligands could also generate cellular oxidative stress. The generation of ROS in A2780 and A2780cis cells after incubation with 1-5, cisplatin, oxaliplatin and IPA was measured. ROS levels were monitored over a $2 \mathrm{~h}$ period using $2^{\prime}, 7^{\prime}$ dichlorofluorescein diacetate $\left(\mathrm{H}_{2} \mathrm{DCFDA}\right)$ as a peroxide-sensitive 


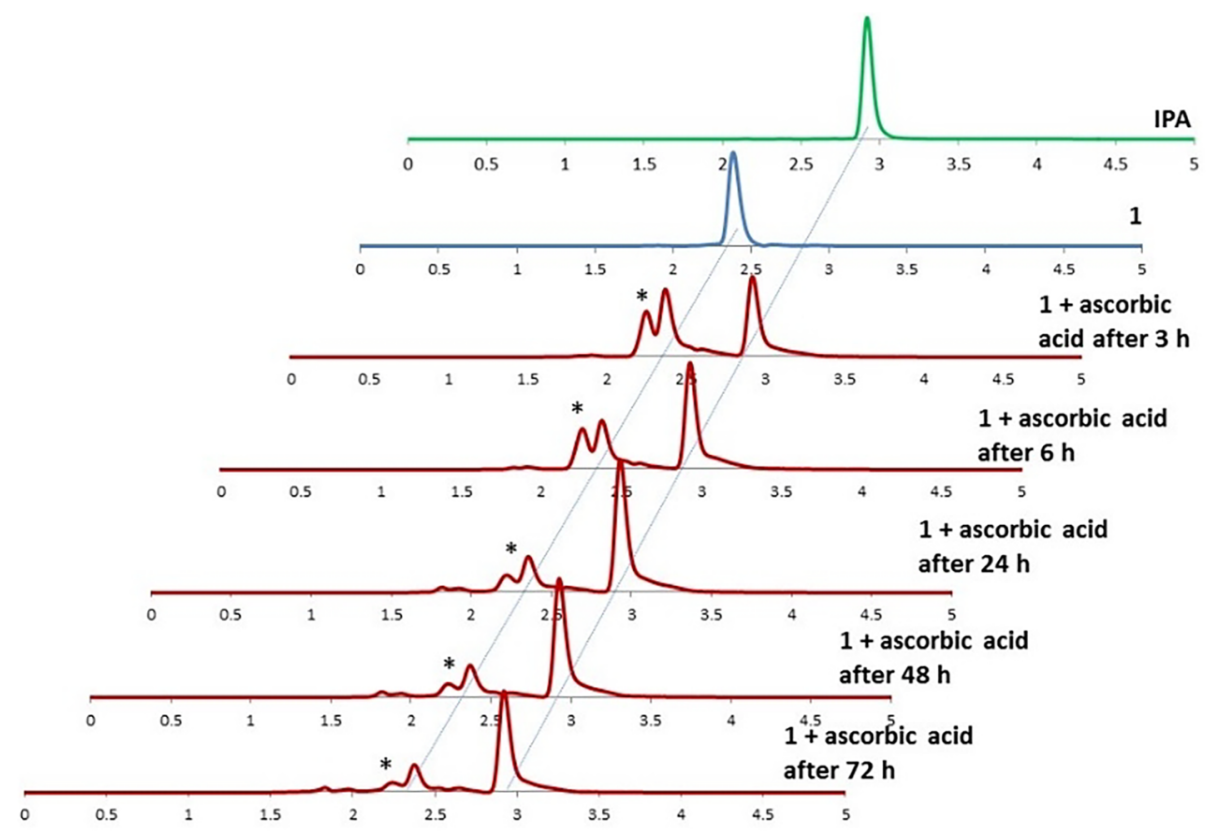

Fig. 1. HPLC analysis of the reaction of 1 with ascorbic acid at $37^{\circ} \mathrm{C}$ and $\mathrm{pH} 7$ at different times. * = ascorbic acid.

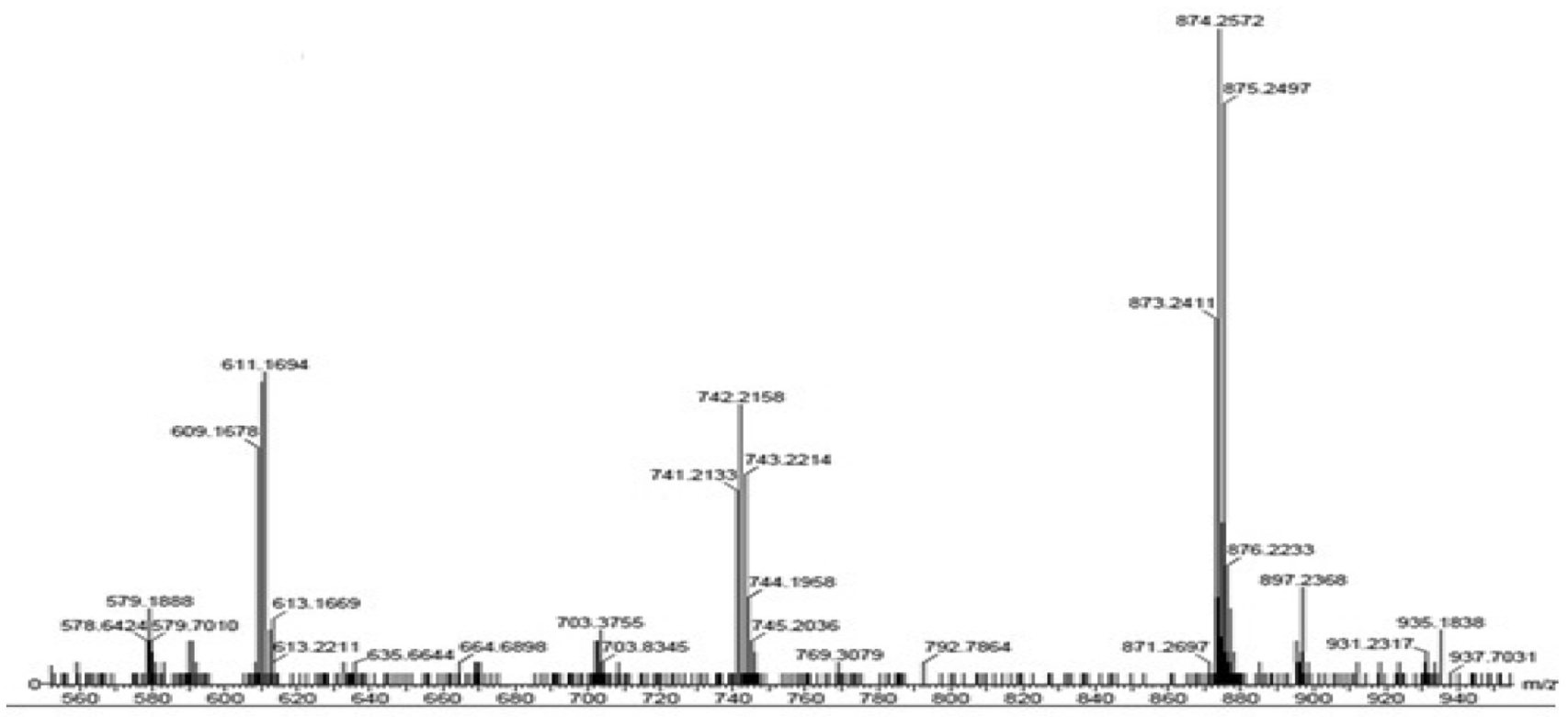

Fig. 2. ESI-MS spectrum of the reaction between 1 and guanosine in presence of sodium ascorbate.

fluorescent dye and the results are reported in Fig. 3 and Fig. 14S in the Supporting Information. All the complexes were able to stimulate the production of ROS in a time-dependent manner and the increased oxidative stress follows the order $1>4>3>2>5$. Complex 1 is the most efficient ROS generator and is significantly more potent than the free IPA ligand and the reference drugs cisplatin and oxaliplatin. The higher cytotoxic activity of complex 1 with respect to the other complexes is probably due to a synergistic effect of the two active species released upon intracellular reduction, oxaliplatin and IPA. As known, while oxaliplatin will interact with DNA as its cellular target, IPA will increase the ROS production with these two mechanisms operating simultaneously.

\section{Conclusions}

The most active complex of the newly synthesized Pt(IV) derivatives of oxaliplatin, cis,cis,trans-[Pt(DACH)(ox)(IPA)(OH)] is more potent than oxaliplatin in A2780 ovarian cancer cells. Overall, compared to their cisplatin-based counterparts reported earlier by us [22], 1-5 are only moderately cytotoxic. This is in line with reports on other oxaliplatin/cisplatin pro-drugs [17] and can be attributed to the relatively slow reduction kinetics of Pt(IV) derivatives of oxaliplatin. 1-5 are more efficient ROS producers in A2780 and A2780cis cells than the free indole carboxylic acid. 


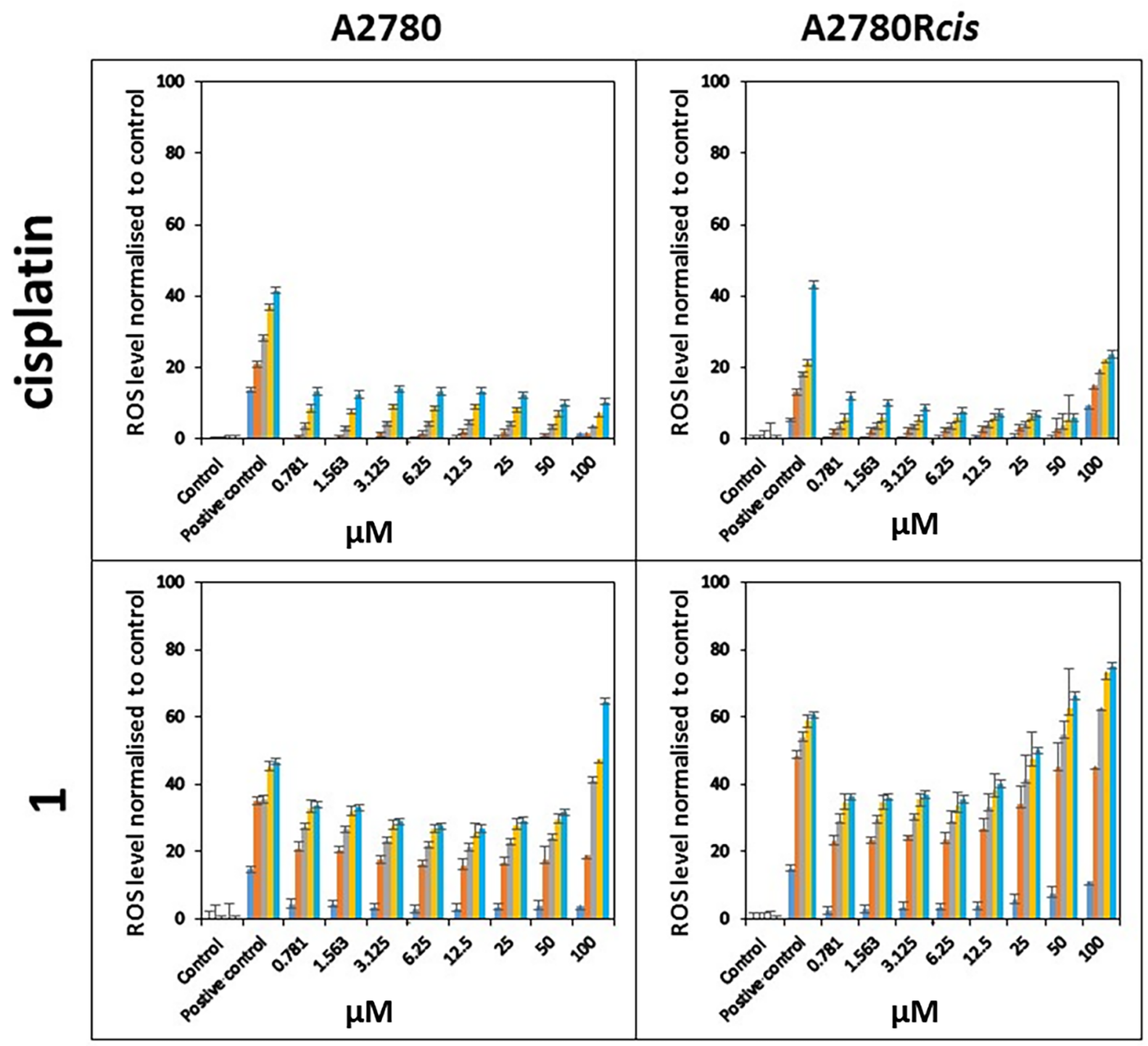

Fig. 3. Fluorescent detection of ROS using DCFDA in A2780 and A2780cis cells after exposure to cisplatin (top) and $\mathbf{1}$ (bottom) over a period of $2 \mathrm{~h} \cdot \mathrm{H}_{2} \mathrm{O}_{2}$ was used as a positive control. $10 \mathrm{~min}$; $15 \mathrm{~min}$; $30 \mathrm{~min}$; $1 \mathrm{~h}$; $2 \mathrm{~h}$.

\section{Acknowledgements}

A.A. acknowledges a PhD scholarship from Taibah University. D.T. acknowledges the Egyptian Ministry of Higher Education (MoHE) for funding her research stay at the National University of Ireland Galway.

\section{Appendix A. Supplementary data}

Supplementary data to this article can be found online at https:// doi.org/10.1016/j.ica.2019.04.038.

\section{References}

[1] M. Galanski, M.A. Jakupec, B.K. Keppler, Curr. Med. Chem. 12 (2005) 2075-2094.

[2] R.B. Mokhtari, T.S. Homayouni, N. Baluch, E. Morgatskaya, S. Kumar, B. Das, H. Yeger, Oncotarget 8 (2017) 38022.

[3] T.C. Johnstone, K. Suntharalingam, S.J. Lippard, Chem. Rev. 116 (2016) 3436-12086.

[4] D. Gibson, J. Inorg. Biochem. 191 (2019) 77-84.

[5] W.H. Ang, I. Khalaila, C.S. Allardyce, L. Juillerat-Jeanneret, P.J. Dyson, J. Am. Chem. Soc. 127 (2005) 1382-1383.

[6] M.R. Reithofer, S.M. Valiahdi, M. Galanski, M.A. Jakupec, V.B. Arion, B.K. Keppler, Chem. Biodiversity 5 (2008) 2160-2170.
[7] S. Dhar, S.J. Lippard, Proc. Natl. Acad. Sci. U.S.A. 106 (2009) 22199-22204.

[8] L.J. Parker, L.C. Italiano, C.J. Morton, N.C. Hancock, D.B. Ascher, J.B. Aitken, H.H. Harris, P. Campomanes, U. Rothlisberger, A. De Luca, M. Lo Bello, W.H. Ang, P.J. Dyson, M.W. Parker, Chem. Eur. J. 17 (2011) 7806-7816.

[9] Q. Cheng, H. Shi, H. Wang, Y. Min, J. Wang, Y. Liu, Chem. Commun. 50 (2014) 7427-7430.

[10] R.K. Pathak, S. Marrache, J.H. Choi, T.B. Berding, S. Dhar, Angew. Chem. Int. Ed. 53 (2014) 1963-1967.

[11] R.K. Pathak, S. Dhar, Chem. Eur. J. 22 (2016) 3029-3036.

[12] K. Suntharalingam, Y. Song, S.J. Lippard, Chem. Commun. 50 (2014) 2465-2468.

[13] L. Ma, R. Ma, Y. Wang, X. Zhu, J. Zhang, H.C. Chan, X. Chen, W. Zhang, S.-K. Chiu, G. Zhu, Chem. Commun. 51 (2015) 6301-6304.

[14] J. Ma, Q. Wang, X. Yang, W. Hao, Z. Huang, J. Zhang, X. Wang, P.G. Wang, Dalton Trans. 45 (2016) (1838) 11830-11831.

[15] Q. Wang, Z. Huang, J. Ma, X. Liu, L. Zhang, X. Wang, P.G. Wang, Dalton Trans. 45 (2016) 10366-10374.

[16] Z. Wang, Z. Xu, G. Zhu, Angew. Chem. Int. Ed. 55 (2016) 15564-15568.

[17] R. Raveendran, J.P. Braude, E. Wexselblatt, V. Novohradsky, O. Stuchlikova, V. Brabec, V. Gandin, D. Gibson, Chem. Sci. 7 (2016) 2381-2391.

[18] V. Reshetnikov, A. Arkhypov, P.R. Julakanti, A. Mokhir, Dalton Trans. 47 (2018) 6679-6682.

[19] Y.N. Nosova, I.V. Zenin, V.P. Maximova, E.M. Zhidkova, K.I. Kirsanov, E.A. Lesovaya, A.A. Lobas, M.V. Gorshkov, O.N. Kovaleva, E.R. Milaeva, M. Galanski, B.K. Keppler, A.A. Nazarov, Bioinorg. Chem. Appl. (2017) 4736321.

[20] A.R.Z. Almotairy, V. Gandin, L. Morrison, C. Marzano, D. Montagner, A. Erxleben, J. Inorg. Biochem. 177 (2017) 1-7.

[21] E. Wexselblatt, D. Gibson, J. Inorg. Biochem. 117 (2012) 220-229. 
[22] D. Tolan, V. Gandin, L. Morrison, A. El-Nahas, C. Marzano, D. Montagner, A. Erxleben, Sci. Rep. 6 (2016) 29367.

[23] J.S. Biradar, B.S. Sasidhar, R. Parveen, Eur. J. Med. Chem. 45 (2010) 4074-4078.

[24] L. Folkes, L. Candeias, P. Wardman, Int. J. Radiat. Oncol. Biol. Phys. 42 (1998) 917-920.

[25] L.K. Folkes, P. Wardman, Biochem. Pharmacol. 61 (2001) 129-136.

[26] M. Karbownik, E. Gitto, A. Lewiñski, R.J. Reiter, J. Cell. Biochem. 81 (2001) 693-699.

[27] B. Poeggeler, M.A. Pappolla, R. Hardeland, A. Rassoulpour, P.S. Hodgkins, P. Guidetti, R.B. Schwarcz, Brain Res. 815 (1999) 382-388.
[28] S. Faivre, D. Chan, R. Salinas, B. Woynarowska, J.M. Woynarowski, Biochem. Pharmacol. 66 (2003) 225-237.

[29] L. Kelland, Nat. Rev. Cancer 7 (2007) 573-584.

[30] T.C. Johnstone, Polyhedron 67 (2014) 429-435.

[31] A.M. Francesco, A. Ruggiero, R. Riccardi, CMLS 59 (2002) 1914-1927.

[32] J.L. Misset, Br. J. Cancer 77 (Suppl. 4) (1998) 4-7.

[33] L. Yang, H. Xiao, L. Yan, R. Wang, Y. Huang, Z. Xie, X. Jing, J. Mater. Chem. B 2 (2014) 2097-2106.

[34] M.R. Reithofer, S.M. Valiahdi, M.A. Jakupec, V.B. Arion, A. Egger, M. Galanski, B.K. Keppler, J. Med. Chem. 50 (2007) 6692-6699. 